\title{
Meluruskan Sejarah Proklamasi Kemerdekaan Indonesia: Suatu Kajian Terhadap Buku Teks Pelajaran Sejarah
}

\author{
Straightening the History of the Proclamation of Indonesian Independence: $A$ \\ Study of History Textbooks
}

\author{
Toto Suharya \\ $\triangle$ SMAN 2 Padalarang Bandung \\ E-mail: master.totosuharya@gmail.com ${ }^{凶}$
}

Diterima: 28 Oktober 2020 | Direvisi: 15 November 2020 | Diterbitkan: 16 November 2020

ARTICLE INFO

Keywords:
The Proclamation of
Indonesian Independence,
Textbook,
Mohammad Hatta,
Adam Malik.

Kata Kunci:

Proklamasi Kemerdekaan Indonesia,

Buku Teks,

Mohammad Hatta,

Adam Malik.

\section{ABSTRACT}

\begin{abstract}
Historical material around the proclamation includes knowledge that must become the collective memory of the Indonesian people. The history of the proclamation became a milestone for the success of the Indonesian nation in breaking away from colonialism. However, according to Hatta, there were many stories and writings that were not true about the Indonesian proclamation. In fact, the importance of writing history cannot be separated from the historical facts that were found. Thus, the objectives to be achieved in this study are to compile historical stories based on primary evidence and find the legitimacy of historical writing based on the theoretical point of view of historical writing for history textbooks. Meanwhile, the method used is literature study. The results show that the writing of the history of the proclamation of Indonesian independence in history textbooks does not reflect a narrative that has considered primary sources, both from the archives and the views of historical actors. The history of the proclamation that circulates in textbooks is dominated by historical stories based on the source of Adam Malik's book. Hatta's book of direct testimony which is more authentic, because as a direct actor in the incident, it is worth considering.
\end{abstract}

Materi sejarah sekitar proklamasi termasuk pengetahuan yang harus menjadi memori kolektif bangsa Indonesia. Sejarah proklamasi menjadi tonggak keberhasilan bangsa Indonesia dalam melepaskan diri dari penjajahan. Namun, menurut Hatta banyak tersiar cerita dan karangan yang tidak benar tentang proklamasi Indonesia. Padahal, kepentingan penulisan sejarah tidak lepas dari fakta sejarah yang ditemukan. Sehingga, tujuan yang ingin dicapai dalam penelitian ini adalah menyusun cerita sejarah berdasarkan bukti primer dan menemukan legitimasi penulisan sejarah berdasarkan sudut pandang teori penulisan sejarah bagi buku teks pelajaran sejarah. Sedangkan, metode yang digunakan adalah studi pustaka. Hasil penelitian menunjukkan bahwa penulisan sejarah proklamasi kemerdekaan Indonesia dalam buku teks pelajaran sejarah, belum mencerminkan narasi yang sudah mempertimbangkan sumber-sumber primer, baik dari arsip maupun pandangan pelaku sejarah. Sejarah peristiwa proklamasi yang beredar dalam buku teks, didominasi oleh cerita sejarah berdasarkan pada sumber buku Adam Malik. Buku kesaksian langsung dari Hatta yang lebih otentik, karena sebagai pelaku langsung dalam perisitwa tersebut layak untuk dipertimbangkan. 


\section{PENDAHULUAN}

"Amat besar kebencian di sisi Allah bahwa kamu mengatakan apa-apa yang tiada kamu kerjakan" (Ash Shaff, 61: 3). Ayat tersebut menyiratkan bahwa para sejarawan diikat oleh Tuhan dengan karakter jujur dalam mengemukakan hasil-hasil temuannya. Maka sejarah yang ditulis berdasarkan sesuatu yang ditemukan. Kebenaran sejarah sangat tergantung pada fakta yang ditemukan. Sejarah yang diceritakan tidak berdasarkan pada kebohongan yang akan mendatangkan keburukan.

Di sisi lain, dalam kurikulum 2013, mata pelajaran Sejarah Indonesia merupakan mata pelajaran wajib yang harus dipelajari peserta didik. Di tingkat SMA, Sejarah Indonesia wajib diajarkan pada semua jurusan. Darmawan (2019) mengungkap data pendidikan nasionalisme dalam buku teks pelajaran sejarah pada masa Orde Baru dan Reformasi. Buku teks masa Orde Baru mengandung pendidikan nasionalisme 40,1\% dan masa Reformasi $59,9 \%$. Buku teks pelajaran sejarah pada masa Reformasi semakin menunjukkan pentingnya pendidikan nasionalisme pada pembelajaran sejarah.

Materi sejarah sekitar proklamasi termasuk pengetahuan yang harus menjadi memori kolektif bangsa Indonesia. Sejarah proklamasi menjadi tonggak keberhasilan bangsa Indonesia dalam melepaskan diri dari penjajahan. Sejarah bukan dongeng, sejarah adalah fakta yang benar-benar terjadi di masa lalu berdasarkan bukti-bukti yang ditemukan. Namun demikian, berdasarkan kesaksian Hatta (1969) banyak tersiar cerita dan karangan yang tidak benar tentang proklamasi Indonesia. Hal ini terjadi karena sejarah ditulis dalam waktu amat dekat dengan pergolakan yang belum selesai, sehingga banyak bercampur antara 'Dichtung und Wahrheit. Gambaran itu lebih banyak memakai warna cita-cita pengarangnya daripada menyerupai kejadian-kejadian yang sebenarnya.

Sejarah menurut paham rekonstruksionisme adalah cerita yang disusun berdasarkan bukti-bukti yang ditemukan. Cerita sejarah tidak bisa direka-reka kecuali mengikuti informasi yang terdapat dalam bukti-bukti sejarah yang ditemukan. Penelitian sejarah seperti menyusun puzzle yang berserakan. Sejarawan tidak bisa berteori untuk menjelaskan yang terjadi di masa lalu. Seluruh kejadian sejarah yang diungkap berdasarkan pada faktafakta sejarah yang ditemukan.

Cerita sejarah mengandung kebenaran bukan sekedar dongeng. Kebenaran sejarah tergantung pada keaslian dan keotentikan sumber yang digunakan sebagai sumber sejarah. Paham rekonstruksionisme sangat teliti dalam menulis cerita sejarah. Sumber-sumber primer yang dijadikan data sejarah harus diverifikasi keaslian sumbernya. Kebenaran sejarah didukung oleh kebenaran-kebenaran empiris yang tidak bisa digugat kecuali ditemukan sumber primer baru.

Menurut Munslow (2006) dalam paham konstruksionisme, sejarawan tidak bisa mengungkap keaslian cerita sejarah yang sebenarnya. Akses sejarawan ke masa lalu sangat terbatas, untuk itu tidak mungkin para sejarawan menjelaskan kejadian sejarah di masa lalu dengan lengkap karena akses ke 
Suharya, 2020, Meluruskan Sejarah Proklamasi ...

masa lalu sangat terbatas. Untuk menjelaskan lebih lengkap dibutuhkan teori-teori lintas disiplin untuk memberikan penjelasan yang memuaskan. Berbeda dengan paham rekonstruksionisme dan konstruksionisme, dekonstruksionisme menekankan pentingnya sejarah bukan pada kebenaran, tetapi pada tujuan penulisan sejarah. Sejarah yang disusun oleh para sejarawan bukan kebenaran, karena kebenaran adalah cerita sejarah yang tidak pernah terungkap. Kekuatan sejarah ada di cerita sejarah yang disusun oleh para sejarawan. Untuk itu aliran dekonstruksionisme lebih peduli pada kepentingan untuk apa sejarah ditulis. Namun, tidak mengabaikan bahwa kepentingan penulisan sejarah tidak lepas dari fakta sejarah yang ditemukan.

Perbedaan narasi sejarah bisa terjadi karena sumber yang berbeda, atau penafsiran berbeda. Jika sejarah disusun berdasarkan ingatan penulis, maka perbedaan narasi sejarah terletak pada penafsiran. Berdasarkan sumber saksisaksi sejarah, terdapat perbedaan dalam menyajikan fakta-fakta sejarah proklamasi Indonesia. Peneliti di sini melakukan dekonstruksi sejarah berdasarkan sumber tertulis dari dua pelaku sejarah yang berada di sekitar peristiwa, dengan permasalahan sebagai berikut: (1) Bagaimanakah cerita sejarah proklamasi berdasarkan kesaksian pelaku sejarah?; dan (2) Bagaimanakah sejarah proklamasi disusun untuk kepentingan pendidikan sejarah?

Ada dua tujuan yang ingin dicapai dalam penelitian ini, yakni menyusun cerita sejarah berdasarkan bukti primer dan menemukan legitimasi penulisan sejarah berdasarkan sudut pandang teori penulisan sejarah bagi buku teks pelajaran sejarah. Sedangkan, manfaatnya adalah memberi masukan berharga kepada dunia pendidikan untuk mengajarkan sejarah pada buku teks mendekati kejadian aslinya dengan muatan-muatan pendidikan karakter.

\section{METODE}

Berdasarkan sumber-sumber tertulis dari pelaku sejarah yang ditemukan, metode penelitian ini menggunakan studi pustaka (Zed, 2018). Dua buku sumber yang merupakan karya tulis pelaku sejarah ketika proklamasi kemerdekaan Indonesia terjadi adalah buku karya Mohammad Hatta berjudul Sekitar Proklamasi yang diterbitkan pertama kali tahun 1969, sedangkan buku yang digunakan peneliti terbitan keempat tahun 1982. Buku berikutnya adalah karya Adam Malik, berjudul Riwayat Proklamasi Agustus 1945 yang diterbitkan pertama kali tahun 1950, sedangkan buku yang peneliti gunakan adalah terbitan keempat tahun 1982.

Isi kedua buku tersebut dibandingkan dengan isi narasi sejarah proklamasi kemerdekaan Indonesia dalam buku teks pelajaran sejarah. Selanjutnya dilakukan verifikasi sumber dan melakukan dekonstruksi sejarah sesuai dengan tujuan pendidikan sejarah. Selanjutnya, peneliti memberikan analisis penulisan buku teks berdasarkan pandangan beberapa teori besar tentang penulisan sejarah.

\section{HASIL DAN PEMBAHASAN}

\section{Sejarah Proklamasi Versi Hatta}

Banyak tersiar cerita dan karangan yang tidak benar tentang proklamasi kemerdekaan Indonesia. Gambaran sejarah banyak memakai warna cita-cita pengarang daripada menyerupai 
kejadian-kejadian yang sebenarnya. Di sinilah terletak kewajiban ilmu sejarah untuk memisahkan 'wahrheit' (benar) dan 'dichtung' (dibuat-buat) (Hatta, 1982). Mohammad Hatta sebagai saksi sejarah melakukan kritik terhadap penulisan sejarah proklamasi yang dinilai bertentangan dengan kejadian yang dia alami. Pandangan beliau sesuai dengan paham rekonstruksionisme bahwa sejarah harus ditulis berdasarkan kebenaran sejarah.

Hatta menilai dalam penulisan sejarah proklamasi kemerdekaan Indonesia telah bercampur dengan dongeng dan legenda.

"Salah satu dari legenda itu ialah, Sukarno dan Hatta hanya bersedia memproklamasikan kemerdekaan Indonesia setelah dipaksa oleh pemuda. Menurut legenda itu, karena Sukarno dan Hatta tidak mau menyetujui desakan pemuda-pemuda untuk memproklamasikan Indonesia merdeka, maka tanggal 16 Agustus pagi mereka dibawa ke Rengasdengklok dan di sana dipaksa menandatangani Proklamasi kemerdekaan itu esok harinya dibacakan di Pengangsaan Timur 56 pukul 10 pagi" (Hatta, 1982: 3).

Menurut Hatta, dirinya, Sukarno, bersama Dr. Radjiman, sudah mendapat janji kemerdekaan sejak beliau diundang Terauci ke Dalat, Vietnam. Lalu, tanggal 14 Agustus 1945 kembali ke Jakarta. Di depan rakyat, Sukarno berpidato, "kalau dahulu saya berkata sebelum jagung berbuah Indonesia akan merdeka, sekarang saya dapat memastikan Indonesia akan merdeka sebelum jagung berbunga" (Hatta, 1982: 23).

Dilanjutkan oleh Hatta bahwa "Jalan revolusioner itu menjadi teka-teki, apabila proklamasi kemerdekaan itu diucapkan oleh Sukarno, yang dari semua bekerja sama dengan
Jepang dan memproklamasikan kemerdekaan, sesudah Jepang mengakui kemerdekaan Indonesia dan pelaksanaannya diserahkan pada Panitia Persiapan Kemerdekaan Indonesia (Hatta, 1982: 11-12).

Hatta merasa gelisah dengan beredarnya riwayat proklamasi yang tidak dia alami sesungguhnya ketika ia menjadi pelaku langsung dari peristiwa proklamasi. Bahkan, pernah ada cerita dibuat-buat bahwa di Rengasdengklok Sukarno dan Hatta menandatangani naskah proklamasi kemerdekaan Indonesia di bawah todongan pistol pemuda. Karangan romantik ini dikutip dari pengarang Amerika Serikat, Mr. Dr. C. Smit dalam bukunya De Indonesische Questie yang terbit tahun 1952. Ketika bertemu di Honolulu pada 1968, Hatta menegor dengan menunjukkan keterangan yang bertentangan, beliau minta maaf, karena ia mengutip cerita itu dalam pengarang Amerika (Hatta, 1982).

\section{Sejarah Proklamasi Versi Adam Malik}

Sedangkan, di dalam bukunya, beberapa keterangan seputar peristiwa di Rengasdengklok dan proklamasi kemerdekaan Indonesia disampaikan oleh Adam Malik.

"Kira-kira jam 4 pagi, keluarlah sebuah auto dari Cikini 71 , orang-orang yang duduk di dalam auto itu, Khairul Shaleh, Sukarni, J Kunto dan Dr. Muwardi. ...Sukarni dan J. Kunto meneruskan perjalanan ke rumah Bung Hatta. Ketika tiba di rumah Bung Hatta, Sukarni menyuruh penjaga untuk membangunkan Bung Hatta. Setelah Bung Hatta bangun, karena kaget, bertanya kepada Sukarni: "Apa maksudnya?" Sukarni menjawab: "Bung (Hatta) lekas-lekas bersiap, karena keadaan sudah memuncak genting, rakyat sudah tidak sabar menunggu lagi. Bung Hatta yang mendengarkan keadaan memuncak dan kejadian-kejadian yang 
Suharya, 2020, Meluruskan Sejarah Proklamasi ...

mungkin membahayakan jiwa itu, barulah ia bersiap-siap, walaupun dengan hati dan perasaan yang agak dongkol, karena dibangunkan dari kesenangan tidurnya itu. (Malik, 1982: 47).

Setelah rombongan tiba di Rengasdengklok, para rombongan diterima oleh komandan tangsi dan stafnya. Mereka terus dibawa ke tempat yang telah disediakan. Untuk Sukarno dan anak istrinya satu ruangan, dan untuk Bung Hatta pun satu ruangan. Hasil dari pertemuan beberapa menit itu, dapat menghilangkan ke ragu-raguan dan kebimbangan Sukarno-Hatta dan barulah mereka mulai mempercayai dan meyakini akan adanya penyerahan Jepang, serta percaya akan siap sedianya seluruh rakyat untuk menyatakan proklamasi kemerdekaan Indonesia. Putusan saat itu dinamakan Persetujuan Rengas Dengklok. Sukarno-Hatta berjanji akan turut dan sedia menandatangani proklamasi kemerdekaan Indonesia, akan tetapi syaratnya harus ditandatangani di Jakarta (Malik, 1982).

Selanjutnya dinyatakan oleh Adam Malik bahwa:

"Sukarni membacakan isi teks proklamasi yang dibawanya; di dalamnya diterangkan: "bahwa dengan ini rakyat Indonesia menyatakan kemerdekaannya. Segala badan-badan pemerintah yang ada harus direbut oleh rakyat dari orangorang asing yang masih mempertahankannya. ... Sayuti Meliklah yang mengetiknya, hingga akhirnya bunyi proklamasi yang disiarkan sebagai berikut; "kami bangsa Indonesia dengan ini menyatakan kemerdekaan Indonesia. Hal-hal yang mengenai pemindahan kekuasaan dan lain-lain diselenggarakan dengan cara seksama dan dalam tempo yang sesingkat-singkatnya" (Malik, 1982: 65).

\section{Dekonstruksi Sejarah Proklamasi dalam}

\section{Buku Teks}

Konstruksi dan pemahaman terhadap peristiwa yang ditulis dalam buku teks pelajaran harus berkaitan dengan tujuan pembelajaran. Pelajaran sejarah merupakan mata pelajaran yang tujuannya memiliki kaitan dengan pembentukan watak bangsa (Mulyana \& Darmiasti, 2009). Ilmu mengalami perubahan zaman, sejarawan pun harus terbuka pada perubahan zaman. Posmodernisme mempertanyakan gagasan-gagasan tentang pengetahuan, kebenaran, realitas, objektivitas, rasionalitas, dan progres dari budaya sains modern di Barat (Wiriaatmadja, 2015). Sejarawan bukan hanya mempertahankan keilmuannya, tetapi diuji juga kreativitasnya untuk beradaptasi dengan zaman. Melalui semangat inilah peneliti melakukan verifikasi terhadap subtansi buku teks sejarah proklamasi kemerdekaan Indonesia berdasarkan sumber dari pelaku sejarah seputar peristiwa proklamasi tersebut.

Sejarah proklamasi dalam buku teks lebih banyak memuat cerita sejarah berdasarkan buku karangan Adam Malik. Narasi sejarah Hatta dan Adam Malik memiliki perbedaan tajam, di antaranya perbedaan waktu, orang, dan latar. Perbedaan ini menunjukkan bahwa penulisan sejarah proklamasi perlu mendapat penelitian khusus untuk meluruskan kembali, sehingga cerita sejarah benar-benar mendekati kejadian aslinya, tidak disusupi oleh tujuan-tujuan pribadi, kecuali untuk kepentingan bangsa.

Menilai tulisan kedua pelaku sejarah, peneliti memberikan apresiasi kepada kedua tokoh yang telah menyumbangkan tulisannya tentang sejarah proklamasi kemerdekaan Indonesia. Tulisan Hatta terlihat sangat alami dan benarbenar menulis cerita berdasarkan ingatannya sebagai pelaku sejarah langsung dalam peristiwa proklamasi kemerdekaan Indonesia. 
Sedangkan, tulisan Adam Malik terlihat sebagai pelaku sejarah, tetapi tidak menjadi pelaku langsung dari kejadian. Ingatannya dalam sejarah proklamasi merupakan versi pengalaman pribadi sebagai pelaku dan melihat kejadian dari beranda, tidak ikut masuk ke dalam rumah sebagai pelaku sejarah langsung proklamasi kemerdekaan Indonesia.

Sejarah proklamasi dalam buku teks yang ada saat ini, jika dibandingkan dengan cerita sejarah versi Hatta, tidak membawa pembentukan watak bangsa Indonesia sebagai bangsa terdidik dan penuh perhitungan dalam mengambil keputusan. Cerita sejarah versi Adam Malik tidak memiliki alur kronologis seperti yang dikisahkan oleh Hatta. Versi Adam Malik memiliki kepentingan kelompok dan orang yang ingin mendapat tempat dalam cerita sejarah tersebut. Sejarah untuk pendidikan sejarah, harus terbebas dari kepentingan pribadi dan kelompok yang dapat menimbulkan fitnah di masyarakat.

Sejarah bukan masa lalu. Sejarah adalah ingatan (memori), interpretasi, dan imajinasi manusia terhadap masa lalu. Tidak ada sejarah yang benar-benar objektif, karena sejarah ditulis sebagai ingatan, interpretasi, dan imajinasi sejarawan. Objektivitas dalam sejarah diukur dari kedekatan tafsir atau imajinasi sejarawan yang bersumber pada fakta-fakta yang ditemukan. Dengan demikian, sejarawan telah dan selalu berkeyakinan secara subjektif bahwa tafsirannya adalah kesungguhan dari kebenaran secara objektif (Absor, 2019).

'History' dengan 'memory' adalah dua hal yang berbeda. Menurut Tamm (2013: 463), "In my view this old debate stands in need of re- conceptualisation, since the concepts of 'history' and 'memory' can hardly be regarded as of the same category." Sejarah dan ingatan tidak bisa dipandang sama. Sejarah adalah pengetahuan tentang masa lalu, dan memori adalah ingatan (tafsiran) terhadap masa lalu yang dipengaruhi oleh agama, bacaan, seni atau mitologi, dan segala sesuatu yang dapat memproduksi cultural memory. Pemahaman seseorang terhadap masa lalu, sangat tergantung pada yang melatarbelakangi ingatannya.

Tamm (2013: 463) melanjutkan:

"Therefore, I find the concept of 'cultural memory' most useful in trying adequately to articulate the relations of history and memory. In terms of cultural memory, history is a cultural form exactly like, for instance, religion, literature, art or myth, all of which contribute to the production of cultural memory."

Pernyataan tersebut dimaksudkan bahwa ingatan seseorang sangat dipengaruhi oleh latar belakang dan kebiasaan yang dimiliki. Masa lalu seseorang tergantung pada ingatan yang ada pada seseorang. Masa lalu diingat berdasarkan pengetahuan yang muncul dalam ingatan. Jika tidak ada dalam ingatan, sejarah akan hilang ditelan zaman.

\section{KESIMPULAN}

Narasi pendidikan sejarah berbeda dengan narasi ilmu sejarah. Narasi pendidikan sejarah memenuhi ketentuan kurikulum dan standar kompetensi dalam bingkai tujuan pembentukan watak bangsa. Pembentukan watak bangsa dalam pendidikan sejarah dimulai dengan menyusun narasi sejarah berdasarkan pertimbangan pada berbagai sumber primer. 
Penulisan sejarah proklamasi kemerdekaan Indonesia dalam buku teks pelajaran sejarah, belum mencerminkan narasi yang sudah mempertimbangkan sumber-sumber primer, baik dari arsip maupun pandangan pelaku sejarah. Sejarah peristiwa proklamasi yang beredar dalam buku teks, didominasi oleh cerita sejarah berdasarkan pada sumber buku Adam Malik. Buku kesaksian langsung dari Hatta yang lebih otentik, karena sebagai pelaku langsung dalam perisitwa tersebut layak untuk dipertimbangkan. Sosok Hatta yang terkenal jujur dan sederhana menjadi kepercayaan tersendiri bagi peneliti terhadap kesaksian Hatta dalam mengungkap cerita proklamasi kemerdekaan Indonesia.

Dibutuhkan sebuah studi khusus untuk mendekonstruksi sejarah proklamasi kemerdekaan Indonesia di dalam buku teks sejarah yang beredar. Dalam era informasi, tidak ada hal rahasia, jika ketidaksinkronan cerita sejarah antara Hatta dan Adam Malik terungkap ke publik, akan merugikan pelajaran sejarah sebagai suatu pelajaran dongeng dan menjadi pelajaran yang kurang diminati oleh peserta didik.

\section{DAFTAR PUSTAKA}

Absor, N. F. (2019). PENGGUNAAN KONSTRUKSI DAN KONSENSUS DALAM KEBENARAN SEJARAH. Prosiding Seminar Nasional Penguatan Riset Dan Luarannya Sebagai Budaya Akademik Di Perguruan Tinggi Memasuki Era 5.0, 304310.

Darmawan, W. (2019). PENDIDIKAN NASIONALISME DALAM PENULISAN BUKU TEKS PELAJARAN SEJARAH SEKOLAH MENENGAH ATAS MASA ORDE BARU DAN REFORMASI DI INDONESIA. Universitas Pendidikan Indonesia.
Hatta, M. (1982). Sekitar Proklamasi 17 Agustus 1945. Jakarta: Tintamas.

Malik, A. (1982). Riwayat Proklamasi Agustus 1945. Jakarta: Widjaya.

Mulyana, A., \& Darmiasti. (2009). Historiografi di Indonesia: dari magis-religius hingga strukturis. Refika Aditama.

Munslow, A. (2006). Deconstructing history. Taylor \& Francis.

Tamm, M. (2013). Beyond history and memory: New perspectives in memory studies. History Compass, 11(6), 458-473.

Wiriaatmadja, R. (2015). Buku Ajar Filsafat IImu: Relevansinya dengan Pendidikan IPS. Bandung: Rizqi Press.

Zed, M. (2018). Metode Penelitian Kepustakaan. Jakarta: Obor. 